Control Freaks: How Online and Mobile

Communication is Reshaping Social Contact - By:

NAOMI SUSAN BARON

Posted by Michael Lambarena on June 092010 11:01:39

\title{
Control Freaks: How Online and Mobile Communication is Reshaping Social Contact
}

The year was 1956. At the time, the word "computer" referred to a roomful of hardware. "Telephones" were bulky black devices, tethered to walls (and, at least in the US, exclusively owned by the phone company). But a new gadget appeared on the scene that was destined to revolutionize our perceptions of technology - and our ability to manipulate it.

The new contraption was a television remote control.

It was called the Zenith Space Command. Using ultrasonic technology, Robert Adler, a Zenith research physicist, made it possible for viewers to stay put on the couch while they changed channels. Over the next half-century, as electronic devices became ever-more ingenious, so did our ability to manage their uses - from wielding remote controls to adjust fan speeds, to making purchases at vending machines with our mobile phones.

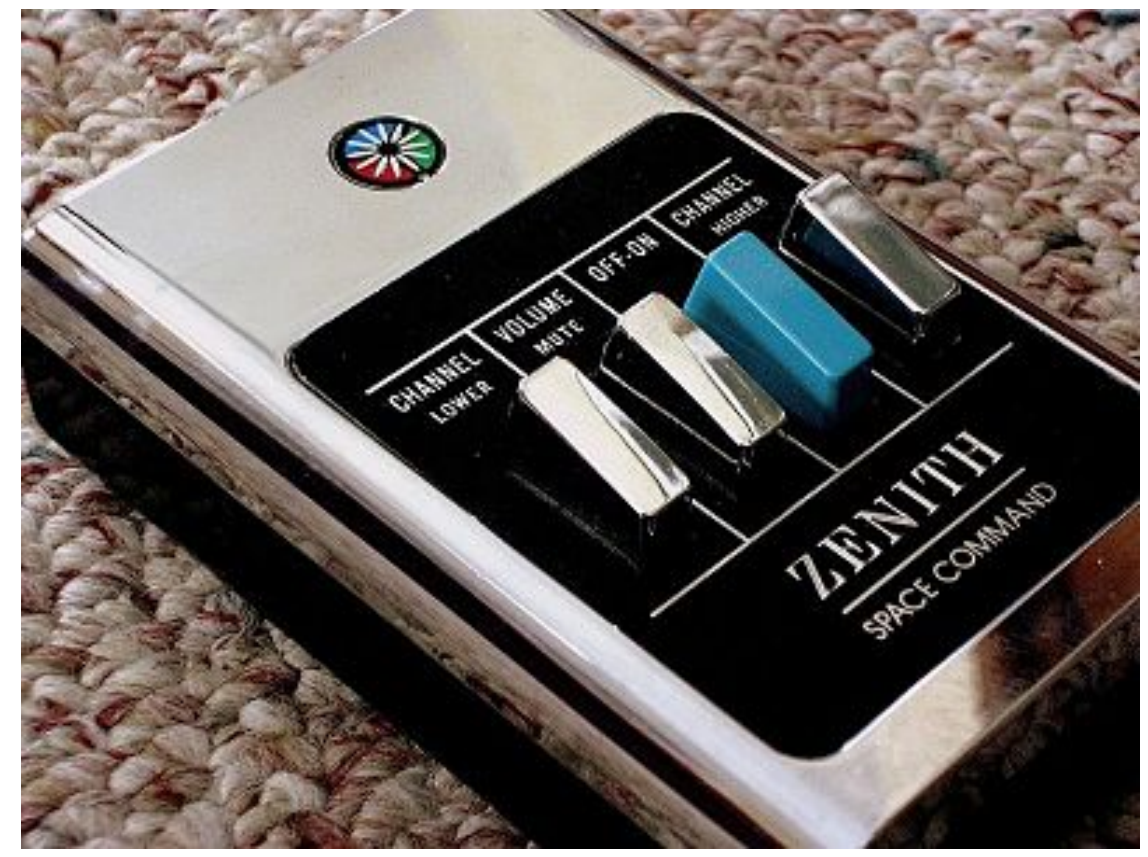


Control has long been a critical aspect of human interpersonal communication. We cross the street to avoid people with whom we do not wish to speak, and we procrastinate in responding to problematic letters. However, with the development of teletechnologies (that is, technologies such as the telegraph, the telephone, and now computers and mobile phones - see Baron 2000), our opportunities for exercising control are scaled up.

Consider the answering machine (whose functions are now subsumed under the name "voicemail"). The earliest prototype dates back to Valdemar Poulsen's Telegraphone (in 1898), with a variety of progressively more sophisticated devices appearing over the years. Answering machines for home use became available in 1971, eventually altering our social perception that when the phone rang, you needed to answer it.

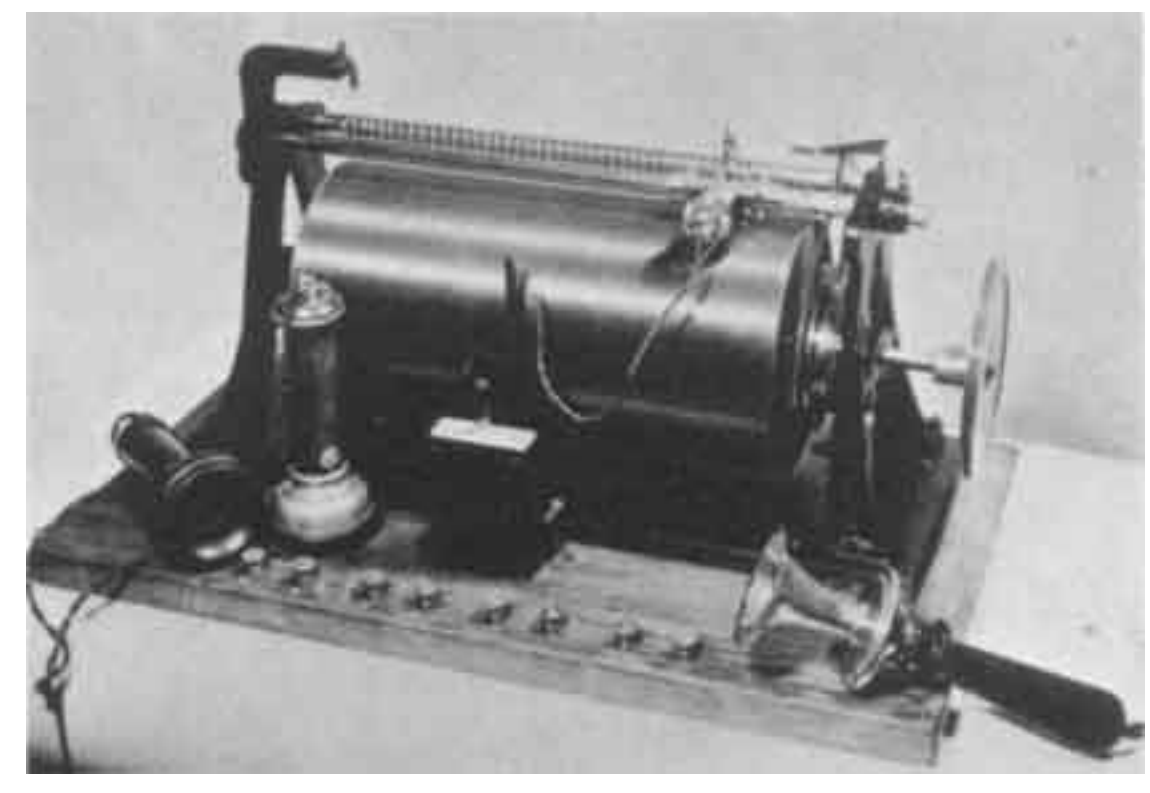

Poulsen's original Telegraphone 


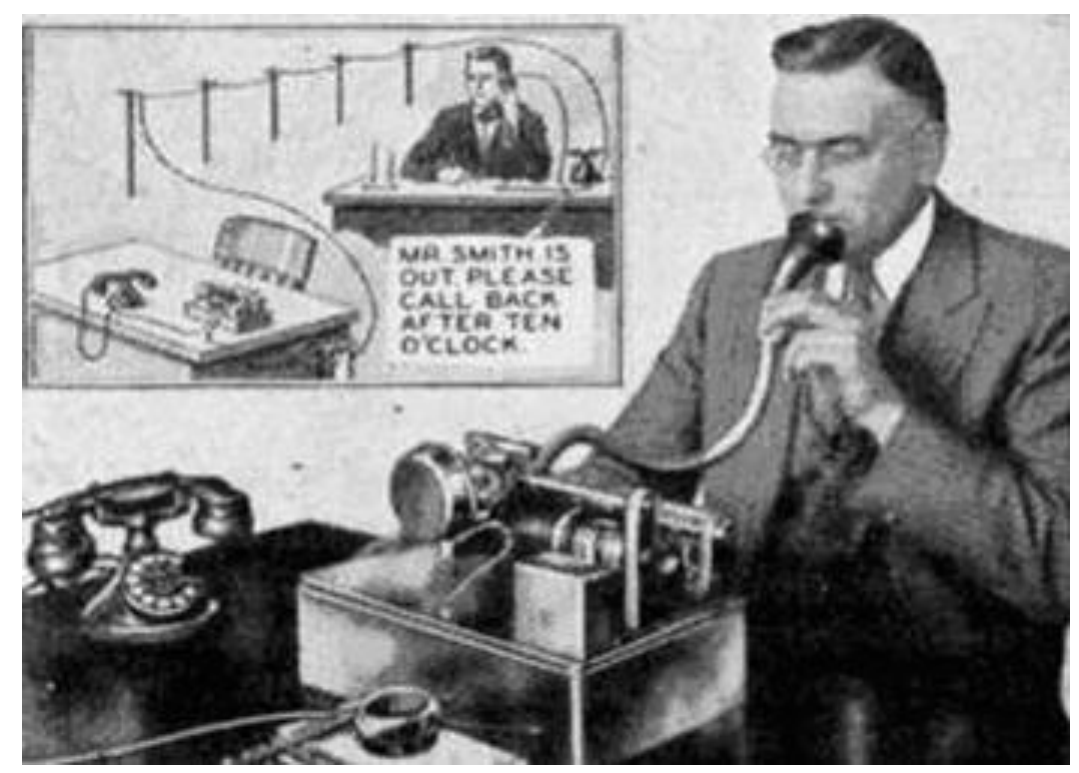

Early answering machine designed for business use

By the end of the twentieth century, landline telephony incorporated a host of additional control mechanisms: caller ID, call waiting, call forwarding, speaker phones. These features (and more) also became part of mobile phone technologies. Meanwhile, developments in computing added control options for both individuals and organizations. Ordinary citizens gained access (e.g., via email) to people who would never have accepted their telephone calls. At the same time, managers could now track the work habits and even the whereabouts of employees.

Another way of exercising control over communication is to do social multitasking, that is, to engage in two or more activities where at least one involves social interaction. For instance, think about talking on the phone while having an IM conversation, or about writing an SMS while sitting at Starbucks with a friend. In studying multitasking behavior of American university students (Baron 2008), I found that $98 \%$ of those surveyed reported engaging in at least one other computer-based or offline behavior while doing IM. However, these same young adults were sometimes uncomfortable when friends with whom they were interacting were socially multitasking. One student complained that "talking on the phone and [simultaneously] talking on the computer [i.e., doing IM] isn't appropriate because the person on the ... phone line usually feels left out or unattended to". In the study of mobile phone use we will be discussing in a moment, a Japanese university student wrote that "many people don't care about other people around them, as they are focusing on their own keitai [mobile phone] completely".

Much ink (actual and virtual) has been spilled over the question 
whether the language used in computer-mediated communication or on mobile phones (particularly regarding texting) is undermining traditional written language (see Thurlow 2006). Empirical research suggests that when it comes to the more obvious features of language such as spelling, syntax, and even lexicon, the answer is largely "no" (Baron 2004, 2008; Crystal 2008). However, a more nuanced question is whether contemporary information and communication technologies (ICTs) such as computers and mobile phones are engendering new ways for us to control communication - or for the technologies to control us.

To help answer this question about ICTs and control, I turned to findings from a cross-cultural study of mobile phone use.

\section{American University Cross-Cultural Mobile Phone Project}

\section{Methodology}

My study surveyed 2001 university students (from Sweden, the US, Italy, Japan, and Korea) regarding where and how they used mobile phones, along with their attitudes concerning the device's virtues and vices. Data were collected between October 2007 and December 2008, using the professional version of SurveyMonkey, a commercial online survey tool. The questionnaire took about 10 minutes to complete and was accessed through a URL link. The survey was originally written in English and then translated into Swedish, Italian, Japanese, and Korean by fluent bilinguals. Participants were a convenience sample of students between age 18 and 24, drawn from two cities in each country. One-quarter of the subjects were male (524), and the remainder were female (1477). Focus groups were also conducted in all countries but Korea.

The survey included a wide variety of questions, including:

-a word association task ("What are the first three words you think of when you think of mobile phones?")

-estimated volume of daily voice calls and text messaging

-preference for doing IM (on a computer) or texting (on a mobile phone)

-determination of who pays the monthly phone costs

-reasons for choosing to text or to talk on the mobile

-attitudes regarding the appropriateness of talking or texting 
while in social space (e.g., having dinner at home with your family, sitting with friends in a café, riding on local transportation)

-pretending to talk on the phone (or playing with other phone functions) to avoid contact with acquaintances or with strangers

-open-ended questions about what subjects liked most and what they liked least about having a mobile phone

Our focus here will be on questions relating to control. (For more information on the larger study, see Baron 2009; Baron \& Campbell ms.; Baron \& Hård af Segerstad 2010.)

\section{Reasons for Choosing to Talk or Text}

Subjects were asked how important it was to send a text message rather than talk because "I want to make my message short, and talking takes too long". Why is talking seen as taking "too long"? Because voice communication affords less control over social interaction than does texting. Voice calls typically require devoting even minimal time to greetings and closings, and there is always the possibility of becoming entrapped in an extended conversation. With texting, you write out what you want to express, send the message, and you're done. (Students in the focus groups confirmed this interpretation of the question.)

Overall, $62 \%$ of the respondents said that keeping the message short was a 'very important' or 'somewhat important' reason for choosing to text. Females were significantly more likely than males to voice this sentiment (females: 64\%; males: 57\%). When the data were divided by country, there were also marked differences. In the three western countries (Sweden, the US, and Italy), between $71 \%$ and $74 \%$ of responses were 'very important' or 'somewhat important'. By contrast, in Japan and Korea, the response rates were only $44 \%$ and $48 \%$, respectively - suggesting that acceptable levels of control in these countries may be less an individual choice than a matter of cultural convention.

A second question involving modality choice related to cost: How important is it to text because "sending an SMS is cheaper". Overall, $56 \%$ of respondents indicated this was a 'very important' or 'somewhat important' reason. Italians had the highest response level (74\%). Not surprisingly, a large proportion of Italians (77\%) were either paying their mobile phone costs themselves or splitting the costs with their parents. (Compare this number with Americans, who reported that parents were paying the entire bill in $74 \%$ of 
cases.) Focus groups in Italy revealed the creative lengths to which Italian university students go to save money on phone use. Every focus group participant described owning two mobiles (generally, one holding a SIM card for the best SMS plan; the other, for the best voice plan). Italian focus group participants also routinely talked about the "missed call" schemes they devised with friends, enabling them to transmit information without incurring costs. (On "missed calls", see Donner 2007.)

\section{Using the Phone to Avoid Acquaintances or Strangers}

Another form of control is using the mobile to avoid conversation. Subjects were asked how often ('at least once a week', 'about once a month', 'occasionally', 'never') they pretended to talk on their phones to avoid talking with someone they knew or to avoid having a stranger talk with them. The strategy turned out to be heavily American. Among the US subjects, $13 \%$ engaged in the practice at least once a month to avoid speaking with an acquaintance, and $15 \%$ did so to avoid a stranger. By way of comparison: Japanese responses for both conditions were $6 \%$ of subjects, and Koreans, $9 \%$ for both conditions. Only $2 \%$ of Italians pretended to talk on their mobiles to avoid acquaintances, and only $4 \%$ of Swedes did so to avoid strangers.

The numbers changed considerably when subjects were asked about playing with other functions on the phone (e.g., reading old text messages or playing a game) 'at least once a month' to avoid encounters with acquaintances or strangers. Americans still led the pack (avoiding acquaintances: 25\%; avoiding strangers: 26\%). However, the percentages rose in all other countries as well. Italian scores remained comparatively low (acquaintances: $8 \%$; strangers: $13 \%$ ). Swedes edged up (acquaintances: $15 \%$; strangers: $18 \%$ ). And Japanese and Koreans were in the low $20 \%$ range for both contexts.

\section{Word Association: Three Words}

The word association task ("What are the first three words you think of when you think of mobile phones?") offered an interesting window into students' attitudes towards their mobile phones. Since there were no pre-established response categories, subjects could write whatever came to mind. Responses ran the gamut from names of telecommunications carriers (e.g., Telenor) to fashion (e.g., snazzy), ancillary functions (e.g., mobile game), 
communication (e.g., keeping in touch), praise for the phone's affordances (e.g., practicality), and complaints about transmission (e.g., how slow), cost (e.g., wasted money), or health-related issues (e.g., brain tumor).

Some responses related to control.

Control can cut two ways. Users might feel that the mobile phone affords them control over their own behavior. Accordingly, a number of responses to the "three words" question were terms such as convenience or fostering independence. Yet by contrast, users might feel that the device imposes external control over them. And indeed, respondents offered words such as addiction, dependency, and even slavery.

\section{Like Most / Like Least}

The double-edged sword of control is even more evident when we look at responses to the two questions "What is the one thing you like most about having a mobile phone?" and "What is the one thing you like least about having a mobile phone?" As with the word association question, subjects were free to respond any way they wished.

For the "like most" question, a number of subjects specifically alluded to issues of control. Here are some examples:

"Constant communication when I want it (can also shut it off when I don't)" (American female)

"Freedom to use where and when I want" (American male)

"The simple fact that I can turn it off when I don't want to be disturbed" (Italian male)

"Can control other people's actions" (Japanese male)

However, there were also many complaints relating to control. For example,

"To be too conditioned by checking calls - almost a fixation" (Italian female)

"To be reached everywhere and even be controlled by the satellite systems" (Italian male)

"I have to call back people or reply to keitai [mobile phone] mails. 
I feel that keitai is controlling us" (Japanese female)

"It controls my action" (Japanese male)

"Feeling under surveillance" (Korean female)

A number of subjects specifically complained about feeling obligated to respond to voice calls or texts ( $6 \%$ of all responses to the "like least" question). Swedes and Americans were most likely to express this complaint (Swedes: 12\% of all "like least" responses; US: 9\% of all "like least" responses). One Swedish female wrote,

"That other people know I can always be reached. So you can never say that you couldn't take the call because everyone knows that you can see missed calls"

An American male said,

"No excuses for not talking to people that I don't want to talk to" while an Italian female complained,

"That others can control you and believe you must always be accessible"

One Italian male concocted an ingenious solution to the problem of feeling controlled:

"At home I put [my mobile phone] in a lead box to avoid being traced (so it does not signal that it is off, but not reachable)"

Other subjects, in responding to the "like least" question, specifically alluded to the issue of dependency. For example,

"It creates an addiction" (Swedish male)

"I hate how dependent I am on it" (American female)

"I am dependent" (Italian female)

"Feel insecure without it" (Korean male)

Overall, $10.5 \%$ of subjects voiced a concern about dependency, with Koreans being the most frequent complainers: fully $30 \%$ of all their "like least" responses. It should come as no surprise that 
Koreans in the study were also the heaviest users of both voice and texting functions on their mobile phones.

Another way of conceptualizing the control issue is in terms of what we called reachability, that is, the ability to use the mobile phone to reach others or for others to reach you. Responses included, for example, "To be able to contact people when I need to", "Contactability", or "Can always be found". When we recoded all the "like most" and "like most" responses with respect to the issue of reachability, we found an interesting love-hate relationship emerging. The results, by country, are summarized in Table 1.

$\begin{array}{llllll} & \text { Sweden } & \text { US } & \text { Italy } & \text { Japan } & \text { Korea } \\ \text { Like most: } & 88 \% & 83 \% & 69 \% & 65 \% & 76 \% \\ \text { Like least: } & 57 \% & 57 \% & 52 \% & 37 \% & 73 \%\end{array}$

Table 1: Reachability (including 'I reach others', 'others reach me', and 'directionality of contact not specified')

In every country, what subjects liked most about having a mobile phone was reachability. However, what people (especially Koreans) complained about most was also reachability -- typically the fact that others could reach them. The low Japanese statistic partly reflects the fact that subjects had other issues to complain about, including the phone's transmission problems and cost. There might also be cultural factors at work, e.g., in Japan it might be considered impolite to complain about others being able to reach you.

\section{Conclusions}

Mobile phone technology affords users a host of new opportunities some obvious and others, less obvious - to exercise control over social interaction. Some degree of active user control was in evidence in each of the countries surveyed in the mobile phone study, though culture seems to play a role in the extent to which a particular technique is utilized (e.g., Americans being far more likely than Italians to pretend to talk on their mobiles to avoid conversation with an acquaintance). 
What is more surprising - and troubling - is the substantial degree to which the same users felt controlled by their own communication technologies. It is reasonable to expect this perception to correlate with volume of mobile phone use (as in the case of Korea). However, there must be more to the story, since Japanese subjects had the next highest volume of text messaging, and they were the least likely to complain about reachability. Rather than drawing hasty conclusions about cross-cultural differences, we will need to look more carefully at cultural parameters to complement our analysis of mobile phone usage (see Baron \& Hård af Segerstad 2010 for an example). But that said, the level of feeling controlled by one's mobile phone was high in each of the countries surveyed.

Do these findings justify a call for action? Does mobile phone use qualify as a practice potentially dangerous to our sense of personal equanimity and social well-being? Or viewed from another perspective, is mobile communication, coupled with the time we spend online with computers (sending email, doing IM, checking Facebook, writing tweets) encroaching upon the rest of our lives? Recent studies of text messaging indicate that one-third of American teenagers are now sending over 100 texts per day (Lenhart et al. 2010). And the Kaiser Family reports that Americans between the ages of 8 and 18 are using entertainment media (e.g., television, video games, MP3 players) an average of 7 hours and 38 minutes per day - a statistic that does not include the daily average of 1 hour and 35 minutes that 7th - 12th graders spend doing text messaging (Kaiser Family Foundation 2010). Once sleeping and eating are accounted for, little time is left in the course of the day for sports or leisure reading - not to mention going to school and doing homework.

It is premature to try predicting the long-term impact of electronically-mediated communication on users' social interactions. For example, it is too soon to know whether the heightened ability to control our access to others - and theirs to us - through ICTs will alter the nature of interpersonal relationships. We cannot foretell whether users will tire of always needing to be on call, with a swing of the social pendulum affording people more personal space, uncoupled from their communication devices. Alternatively, the patterns we have reported in this article may portend a new normal, with the possibilities and pressures of being (and others expecting us to be) digitally available only growing. In each of these scenarios, it remains to be seen whether current differences across cultures are retained or yield to more global influences.

What we do know is that the genie is out of the bottle. Computers and mobile phones are powerful devices that are sure to expand in their uses, including for communication. As researchers of these 
media, we have a responsibility to chart not only the positive value that new media can add to our lives but also the potential danger signs from overuse. As with too much chocolate or too much salt, when it comes to using ICTs, we might do well to heed the advice of the Delphic Oracle: Nothing in excess.

\section{Author}

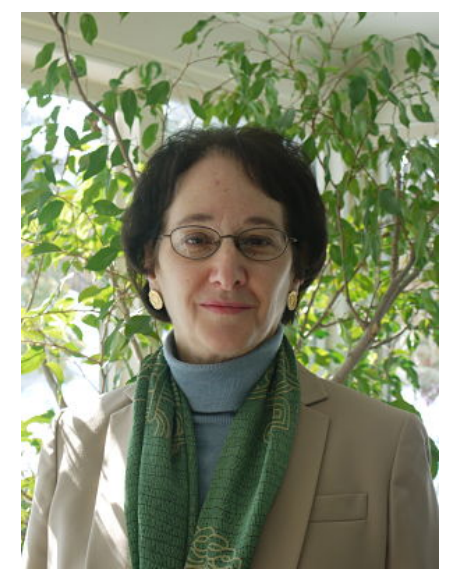

Naomi S. Baron, PhD (Linguistics) is Professor of Linguistics in the Department of Language and Foreig। Studies at American University, in Washington, DC.

A former Guggenheim Fellow and Fulbright Fellow, sh، is the author of seven books. The most recent, Always On: Language in an Online and Mobile World (Oxford 2008), was winner of the 2008 English-Speak Union Duke of Edinburgh English Language Award.

In addition to her cross-cultural research on mobile phones, she is launching a study that compares readir done onscreen versus in hard copy. nbaron@american.edu

\section{References}

Baron, N.S. (2000). Alphabet to email: How written English evolved and where it's heading. London: Routledge.

Baron, N.S. (2004). 'See you online': Gender issues in college student use of instant messaging. Journal of Language and Social Psychology 23(4): 397-423.

Baron, N.S. (2008). Always on: Language in an online and mobile world. New York: Oxford University Press.

Baron, N.S. (2009). Three words about mobile phones: Findings from Sweden, the US, Italy, Japan, and Korea. In B. Sapio, L. Haddon, E. Mante-Meijer, L. Fortunati, T. Turk, and E. Loos (eds.), The good, the bad, and the challenging: The user and the future of information and communication technologies. COST Action 298. Participation in the Broadband Society, vol. 1, pp. 273-282.

Baron, N.S. \& Campbell, E. (ms.). Talking takes too long: Gender 
patterns in mobile telephony. Washington, DC: American University. Baron, N.S. \& Hård af Segerstad, Y. (2010). Cross-cultural patterns in mobile phone use: Public space and reachability in Sweden, the USA, and Japan. New Media \& Society 12(1): 13-34.

Crystal, D. (2008). Txtng: The Gr8 Db8. Oxford: Oxford University Press.

Donner, J. (2007). The rules of beeping: Exchanging messages via intentional 'missed calls' on mobile phones. Journal of ComputerMediated Communication 13(1). Available at http://jcmc.indiana.edu/vol13/issue1/donner.html

Kaiser Family Foundation (2010). Generation M2: Media in the lives of 8- to 18-year-olds. Report available at http://www.kff.org/entmedia/8010.cfm

Lenhart, A., Ling, R., Campbell, S., \& Purcell, K. (2010). Teens and mobile phones. Pew Internet \& American Life Project, April 20.

Available at http://www.pewinternet.org/Reports/2010/Teens-andMobile-Phones.aspx.

Thurlow, Crispin (2006). From statistical panic to moral panic: The metadiscursive construction and poplar exaggeration of new media language in print media. Journal of Computer-Mediated

Communication 11(3). Available at

http://jcmc.indiana.edu/vol11/issue3/thurlow.html

This article was uploaded to http://www.languageatwork.eu in July of 2009 and published under a "Creative Commons license Attribution Non-commercial (by-nc)" for more information please go to: http://creativecommons.org/about/license/ 